\title{
Vitelliform dystrophy and pattern dystrophy of the retinal pigment epithelium: concomitant presence in a family
}

\author{
GIUSEPPE GIUFFRE AND GAETANO LODATO \\ From the Istituto di Clinica Oculistica dell'Università, Palermo, Italy
}

SUMmaRY We describe three siblings presenting unusual pigmented dystrophic lesions of the fovea. The first sibling showed macroreticular dystrophy associated with butterfly shaped dystrophy in one eye and associated with vitelliform cyst in the other eye. The second showed the atrophic outcome of a vitelliform cyst with development of subretinal neovascular membrane in one eye and a radial pigmented macular dystrophy in the other eye. The third sibling had bilateral macular vitelliform lesions. This vitelliform patterned dystrophy of the retinal pigment epithelium may represent a new form that should be classified near Best's disease and the pattern dystrophies.

Pattern dystrophy is a term proposed some years ago $^{12}$ to define a group of dystrophies of the posterior pole of the eye characterised by the arrangement of clumps of retinal pigment in a figure-like fashion. The better known pattern dystrophies are reticular dystrophy, ${ }^{3}$ butterfly-shaped dystrophy, ${ }^{4}$ and macroreticular dystrophy. ${ }^{5}$

Best's disease ${ }^{6}$ is a dystrophy of the retinal pigment epithelium whose appearance, at least at its onset, is that of a cyst of orange coloured material deeply located in the macula. Moreover vitelliform dystrophic lesions resembling those of Best's disease have recently been found associated with pattern dystrophies. ${ }^{78}$

Many features are common to pattern dystrophies, Best's disease, and vitelliform dystrophy: the presence of pigmented material in the retinal pigment epithelium, the usually autosomic dominant inheritance, and the reduced or flat electrooculogram with a normal electroretinogram. These characteristics and the possibility of finding together patterned lesions with vitelliform lesions suggest that all these dystrophies may be correlated.

Here we report on a family in whom an association between various patterned and vitelliform pigmentary dystrophic lesions in different stages of evolution was found.

Correspondence to Dr Giuseppe Giuffrè, Istituto di Clinica Oculistica, Via L Giuffrè 13, 90127 Palermo, Italy.

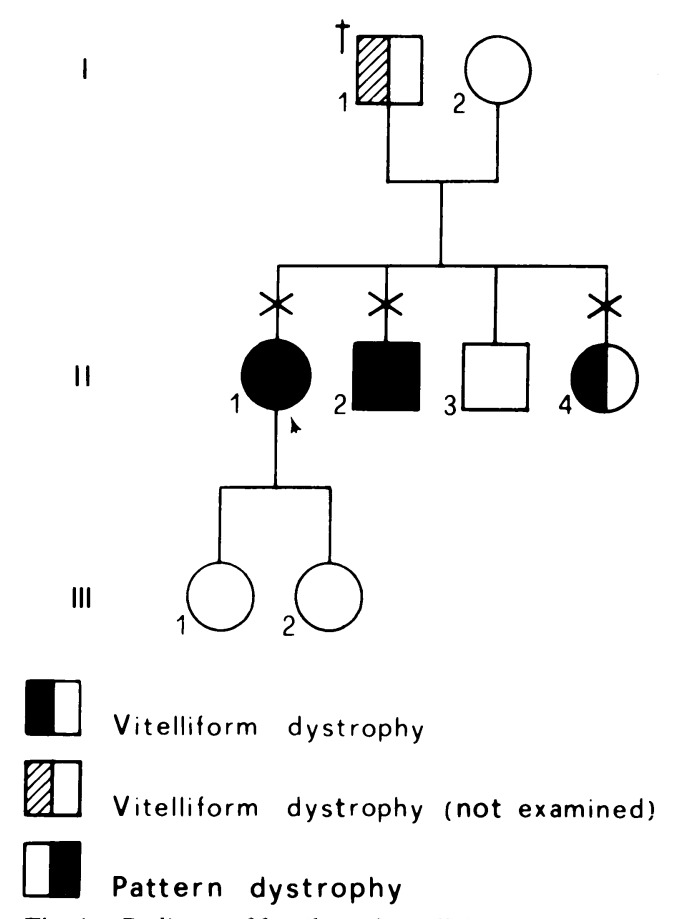

Fig. 1 Pedigree of family with vitelliform dystrophy-pattern dystrophy of the retinal pigment epithelium. Autosomal dominant transmission is strongly suspected. 


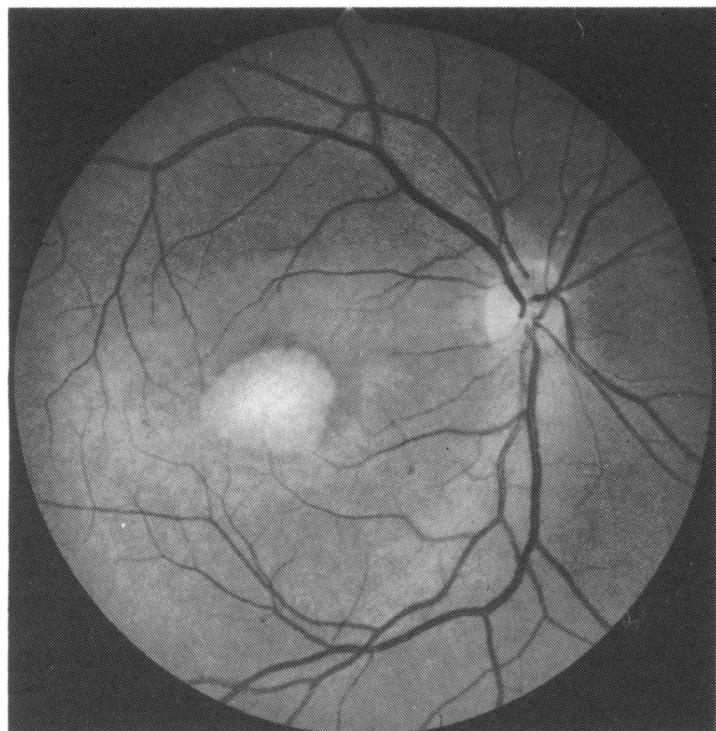

Fig. 2 Case 1. An area of atrophy surrounded by some pigmented lesions is seen in the right macula.

\section{Case reports}

\section{CASE 1}

This 26-year-old woman, the proband of the family shown in Fig. 1 (patient II, 1), had a history of abrupt visual loss in her right eye five months before we saw her. The corrected visual acuity was $20 / 100$ in the

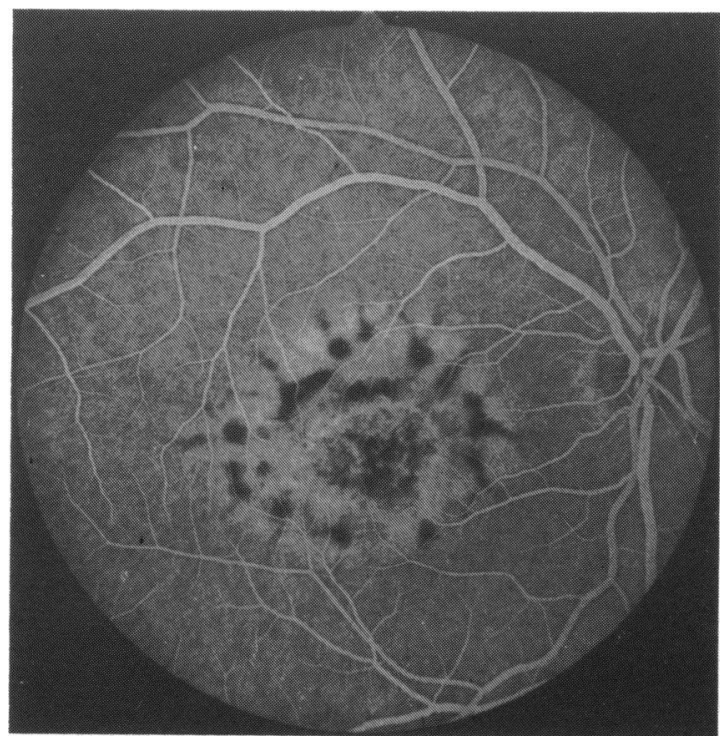

Fig. 4 Case 1. Fluorescein angiography of the right eye, in the early venous phase, shows a net of subretinal macular capillaries. A crown of hypofluorescent lesions surrounds this zone.

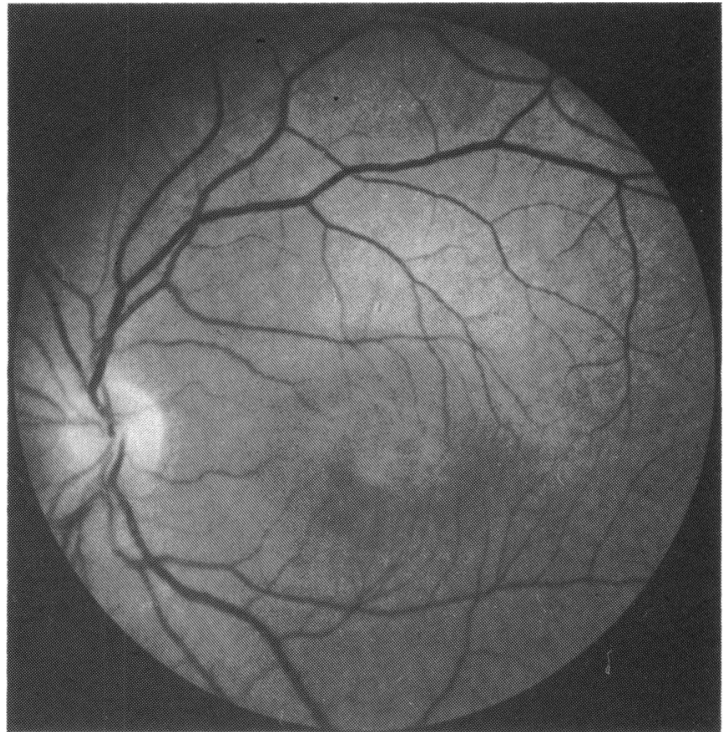

Fig. 3 Case 1. Barely visible subretinal deposits occupy the left macular area.

right eye and 20/25 in the left eye. The anterior segment, intraocular pressure, and vitreous were normal.

Examination of the right fundus disclosed a round area of macular atrophy surrounded by small clumps of pigment (Fig. 2). In the macula of the left eye a subretinal greenish lesion was noted (Fig. 3).

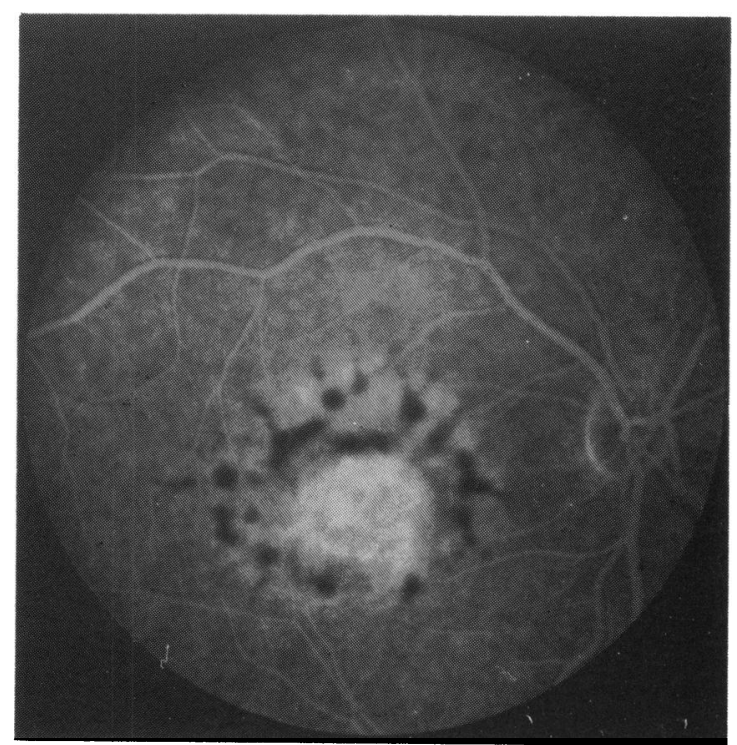

Fig. 5 Case 1. In the late venous phase the subretinal choroidal neovascular membrane of the right eye shows profuse leakage. 


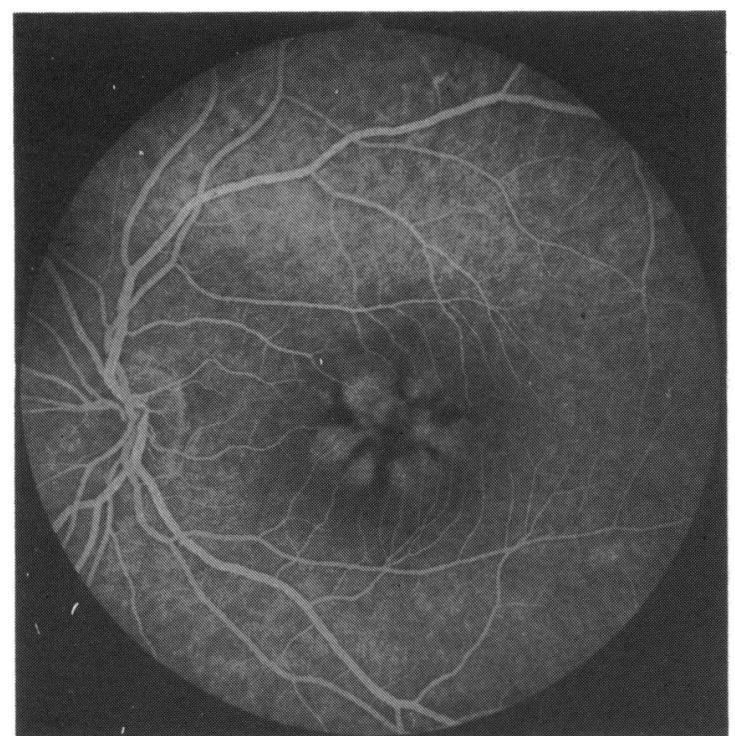

Fig. 6 Case. 1. Fluorescein angiography of the left eye shows some hypofluorescent, radially orientated, macular lesions intermingled with hyperfluorescent areas.

Fluorescein angiography in the right eye revealed, under the atrophic area, a neovascular choroidal membrane leaking fluorescein in the venous phase (Figs. 4, 5). Many hypofluorescent dots scattered in a background of transmitted fluorescence surrounded the lesion. The left macular showed hypofluorescent radial streaks intermingled with hyperfluorescent zones (Fig. 6).

Kinetic visual fields (Goldmann perimeter) showed a reduced central sensitivity in the right eye. Colour sense, with the pseudoisochromatic tables of Ishihara, was normal. The scotopic and photopic electroretinograms recorded by the method used in our laboratory, ${ }^{9}$ were normal. The electro-oculogram showed a flat curve in both eyes with absence of the light rise.

\section{CASE 2}

The 25-year-old brother of the proband (patient II, 2) complained of seing a shadow with his right eye. The corrected visual acuity was $20 / 25$ in the right eye and $20 / 20$ in the left eye. The anterior segment, intraocular pressure, and vitreous were normal.

Fundus examination showed a foveal yellow-green dot located under the retina in both eyes (Figs. 7, 8). Small yellow dots and streaks similar in appearance to the foveal lesion were distributed along the first tract of the superotemporal arcade.

Fluorescein angiography showed masking hypofluorescence of the lesions surrounded by hyperfluorescent areas. The macular lesion in the right eye

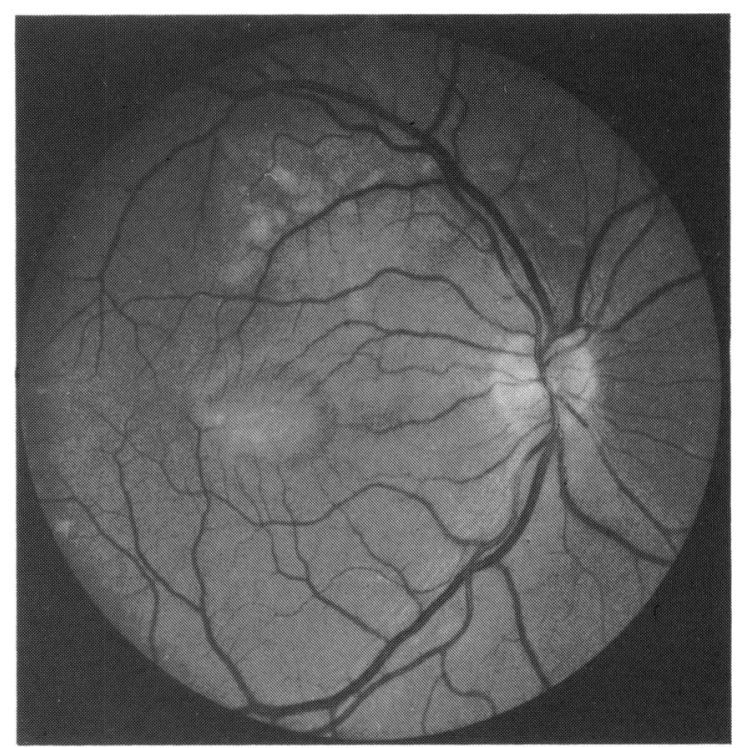

Fig. 7 Case 2. Right eye. A round pigmented lesion is seen in the macular area. Along the superior temporal arcade there are punctate and linear deposits.

(Fig. 9) was triangular and its major axis was one disc diameter wide, while in the left eye (Fig. 10) it was round and smaller. The pigmented streaks outlined a rough network above the macula.

Goldmann perimetry showed a small central scotoma with the target $0 / 1$ in the right eye and normal features in the left eye. Colour sense was normal as

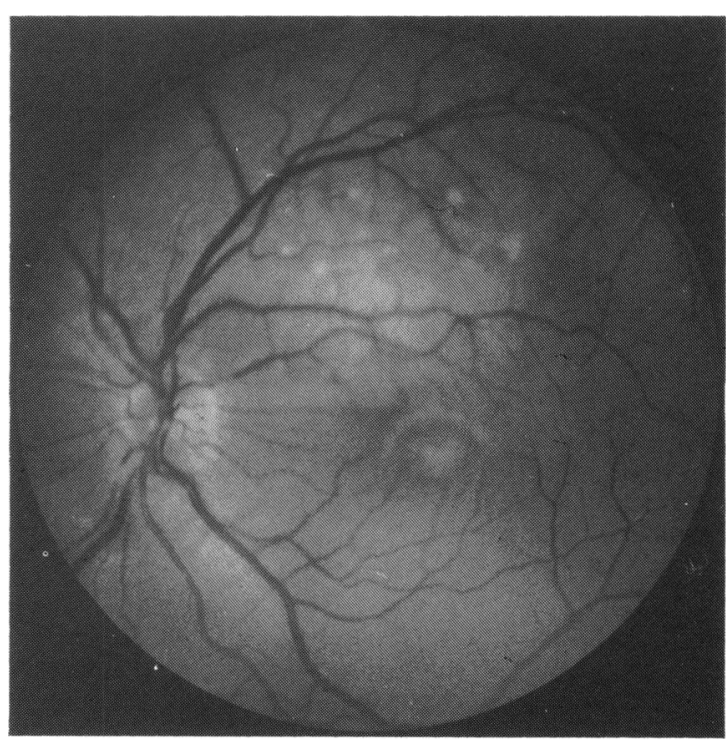

Fig. 8 Case 2. In the left eye pigmented lesions similar in appearance to those of the contralateral eye are seen. 


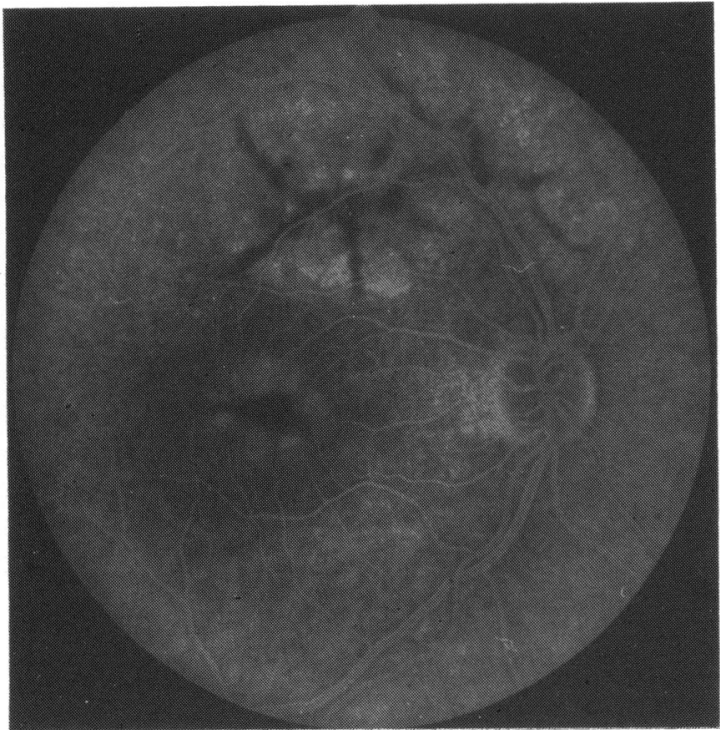

Fig. 9 Case 2. In the right eye fluorescein angiography displays a triangular hypofluorescent macular lesion with a branching pattern in the upper posterior pole. The nearby fundus appears hyperfluorescent.

well as the scotopic and photopic electroretinograms. The electro-oculogram showed a very poor light rise with pathological Arden ratio (116 in both eyes).

\section{CASE 3}

The 18-year-old sister of the proband (patient II, 4) did not present with visual troubles. The visual acuity

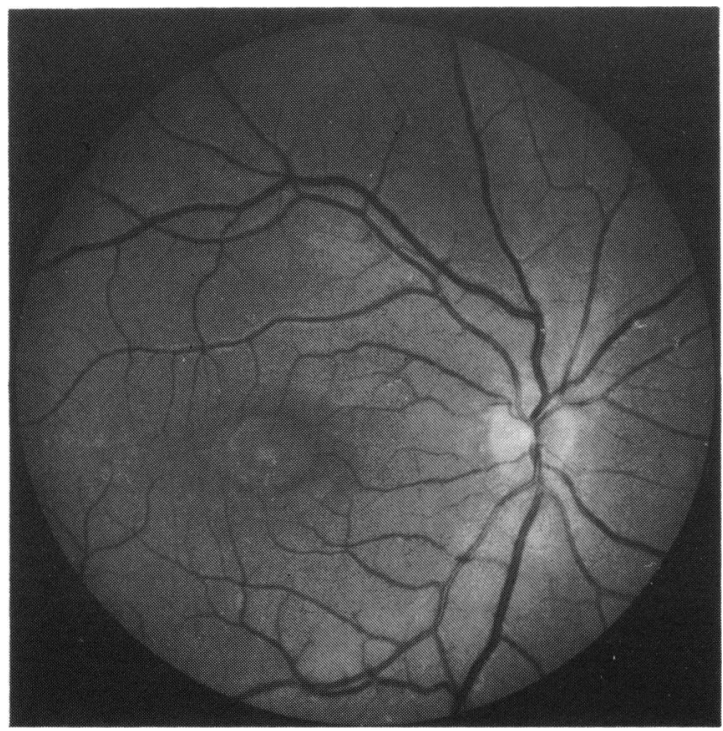

Fig. 11 Case 3. The fundus of the right eye shows a pigmented subretinal central dot.

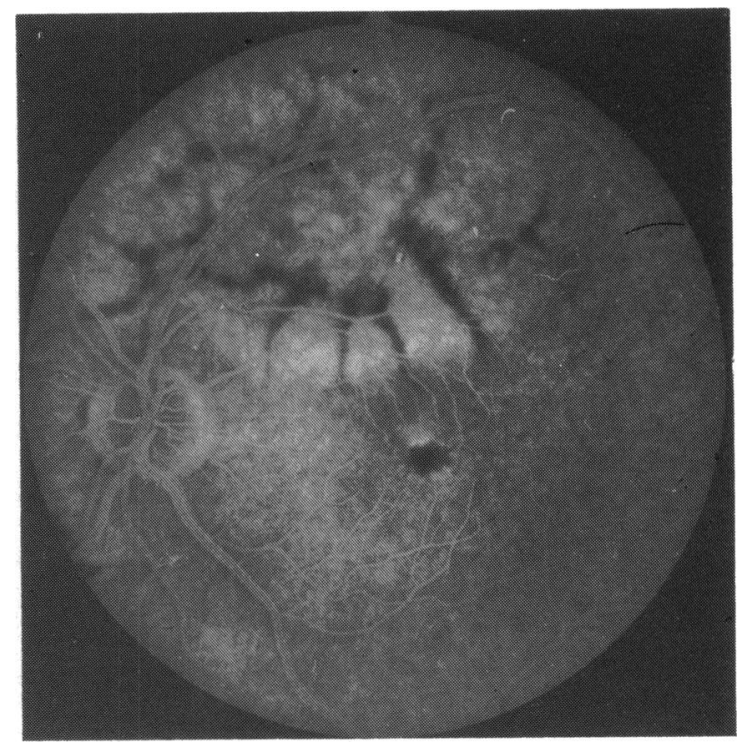

Fig. 10 Case 2. Fluorescein angiography of the left posterior pole shows a round foveal hypofluorescent plaque surmounted by a reticular lesion.

was $20 / 20$ bilaterally. Nothing abnormal was found except in the fundus.

The fundus examination disclosed a round pigmented dot about half a disc diameter wide in the macula of both eyes (Figs. 11, 12).

The dots were hypofluorescent from the early phase of fluorescein angiography and were sur-

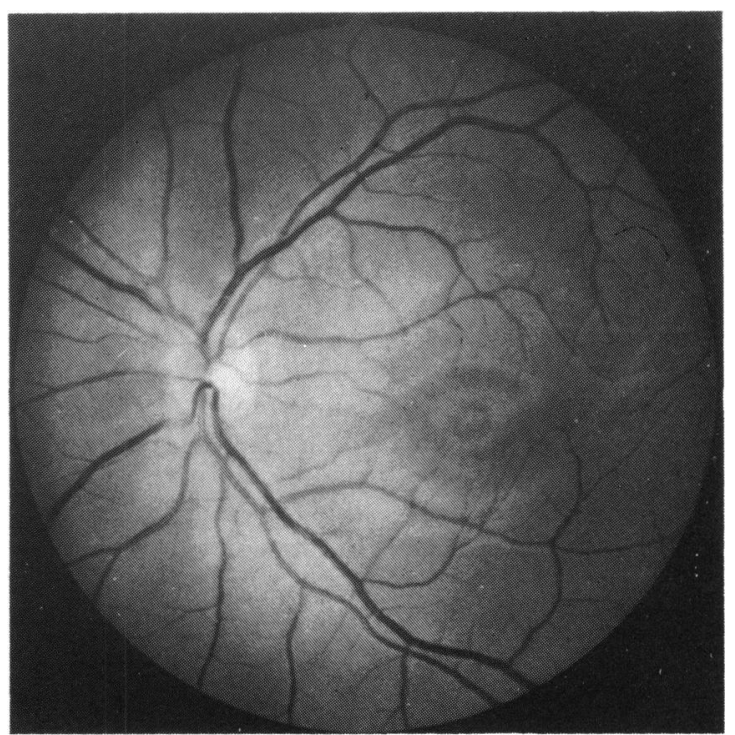

Fig. 12 Case 3. The left macular displays the same features of the right eye. 


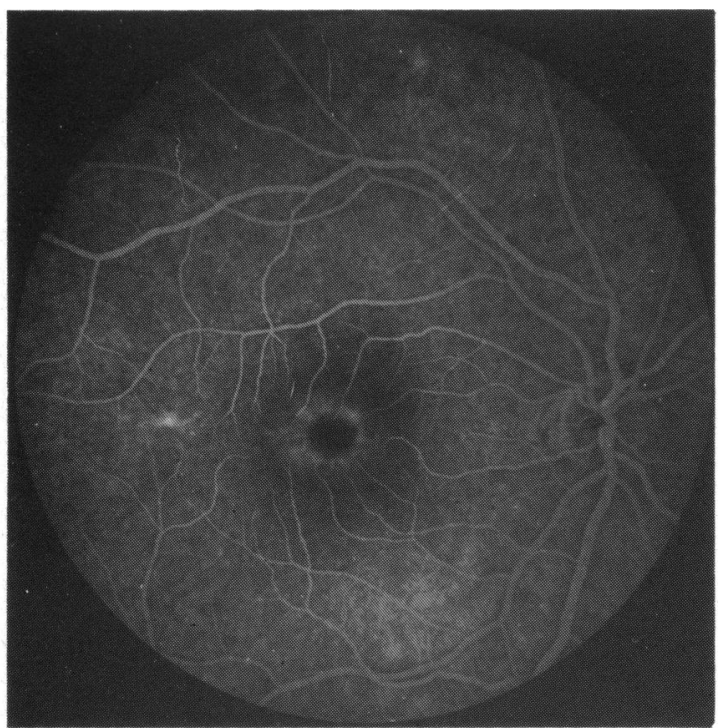

Fig. 13 Case 3. Fluorescein angiography of the right eye. The macular lesion is hypofluorescent and it is surrounded by a hyperfluorescent pigment epithelial defect.

rounded by a ring of transmitted fluorescence due to atrophy of the retinal pigment epithelium (Figs. 13, 14).

Visual fields, colour sense, and electroretinogram were normal. The electro-oculogram showed absence of light rise $($ Arden ratio $=100)$ in both eyes.

It was impossible to examine the fourth sibling and the other members of the family. The father had been diagnosed before his death as having vitelliform dystrophy.

\section{Discussion}

The posterior poles of the retina of these three siblings show unusual pigmentary changes. The first sibling has in his right eye a central area of chorioretinal atrophy with subretinal neovascular membrane that probably represents the evolution of a vitelliform dystrophy. Round this lesion there are radial pigmentary streaks intermingled with areas of pigment epithelium rarefaction. In the left eye macular atrophy is absent, but there are pigmentary streaks in the fovea like those of the contralateral eye. In the second case the macular lesion of the right eye recalls the butterfly-shaped dystrophy of Deutman, while in the left eye the macular pigmentary material has a circular arrangement like vitelliform dystrophy. Above the optic disc there is a pigmentary lesion with a branched pattern like an eccentric macroreticular dystrophy. In this case too the pigment epithelium atrophy alternates with the

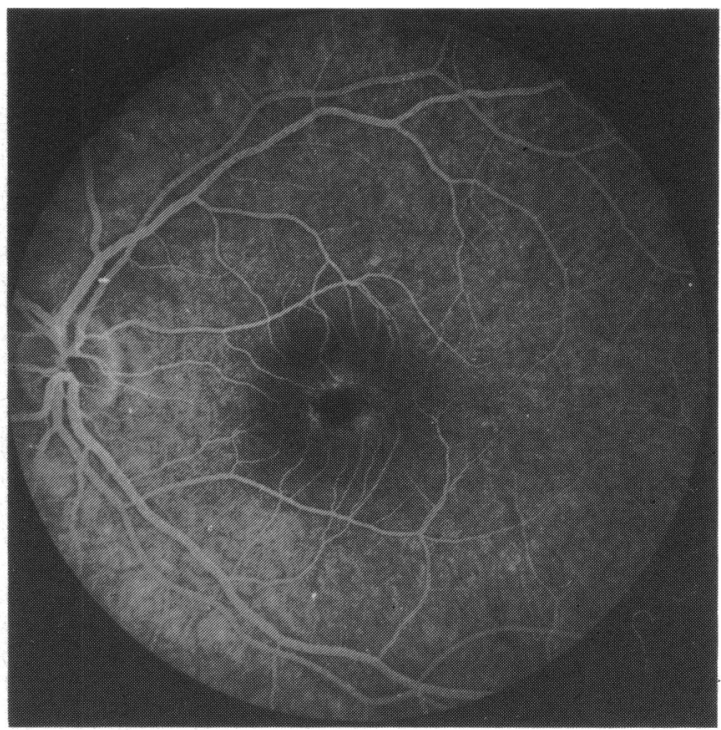

Fig. 14 Case 3. In the left eye too fluorescein angiography shows a hypofluorescent central lesion highlighted by a ring of transmitted hyperfluorescence.

hyperpigmentation. The third case shows a bilateral pigmentary change like vitelliform dystrophy surrounded by a ring of pigmentary rarefaction.

In all three cases the electro-oculogram is much impaired and the electroretinogram normal. Visual acuity is always good, with the exception of the eye with macular neovascularisation (case 1). The mode of inheritance of the lesions is probably autosomal dominant, but this can not be affirmed with certainty.

The macular lesions are obviously different expressions of a single pathological entity. It is probable that in all cases the pigmentary lesions are located, at least at the beginning, in the retinal pigment epithelium. The nature of the pigment is obscure: it could be composed of lipofuscin or some other material. However, no pattern dystrophy has been histologically examined so far. Recently the presence of lipofuscin in the retinal pigment epithelium in Best's disease was histologically proved..$^{11}{ }^{11}$ Probably deposits of lipofuscin-like material also develop, in vitelliform dystrophy and in the pattern dystrophies, possibly owing to an enzymatic defect which reduces their degradation. ${ }^{8} 12$

The lesions seen in the family presented here have not been reported in other pattern dystrophies. Although some features of these lesions are common to previously described pattern dystrophies, they have enough distinctive features to allow us to regard this dystrophy as a new variety of the disease.

In particular, while the presence of various patterned pigmented lesions in members of the same 
family has often been described, ${ }^{12}{ }^{12-14}$ the association between patterned lesions and vitelliform lesions in a pedigree is much rarer. Some such associations have been reported, and these cases have features recalling the lesions here described, but no one of these single cases or families have all the characteristics of our pedigree. Gutman et al. ${ }^{7}$ described a patient with vitelliform macular dystrophy in one eye and butterfly-shaped dystrophy in the other eye, and we ${ }^{8}$ reported a case of vitelliform dystrophy associated with macroreticular dystrophy. A few other reports of this association have been described. ${ }^{15-17}$ In all these cases the dystrophy was a vitelliform lesion surrounded by radial pigmented lines.

The resemblance between the vitelliform dystrophy that we observed and classic Best's disease is worth noting. Besides the similar morphological appearance the two forms have in common the flat electrooculogram, the normal electroretinogram, and the autosomal dominant inheritance. So it is possible that vitelliform dystrophy represents a form of Best's disease associated with pattern dystrophy. However, at present it is preferable to restrict the term Best's disease to that entity which shows only round, dystrophic lesions of the pigment epithelium of the posterior pole, as described by Best, ${ }^{6}$ and to define by the generic descriptive term 'vitelliform dystrophy' the lesions morphologically like the former but associated in the same patient or in other members of the family with patterned lesions.

A difference between vitelliform dystrophy and the pattern dystrophies lies in the alteration of the fundal lesions and the consequent visual outcome. The evolution of vitelliform dystrophy is probably similar to that of Best's disease, whose stages are well known. ${ }^{18}{ }^{19}$ In the early phases the lesion appears as a subretinal and hemispheric macular mass consistent with normal or slightly subnormal visual acuity. Subsequently the material of the cyst may precipitate in the inferior part of the cyst giving an appearance of pseudohypopion or can fragment, thus resembling scrambled eggs. In this stage the visual acuity is generally low. However, other vitelliform lesions never progress and others can even be reabsorbed. Their evolution may be more unfavourable, and the development of a subretinal neovascular membrane may ensue. . $^{21}$

Generally the event that causes the reduction of vision is fragmentation of the cyst. The reason for the rupture is not known. Probably an increase of the material in the cells of the retinal pigment epithelium causes their rupture. ${ }^{19}$ This material spreads in the extracellular spaces and damage to the photoreceptors can follow..$^{10}$

In the pattern dystrophies visual acuity is usually good in young patients but may become worse in the older people..$^{14223}$ On the other hand in these dystrophies a dramatic and abrupt loss of vision as in Best's disease (and in vitelliform dystrophy) is never observed. This may be owing to the small dimensions of the macular lesions in the pattern dystrophies, which, affecting only a few cells of the retinal pigment epithelium, make an acute evolution with development of pseudohypopion or scrambled eggs lesion improbable. Although no follow-up of pattern dystrophies has been long enough to demonstrate their true evolution, we may presume that the macular lesion slowly progress, passing through a phase of pigmentary disorganisation and a later phase of atrophy.

Thus Best's disease and the various pattern dystrophies seem to have many clinical resemblances and some differences, especially in the morphology and the dimensions of the lesions. Some features of these two dystrophies are present in vitelliform pattern dystrophy, which may represent a new form correlated with the other dystrophies of the retinal pigment epithelium.

\section{References}

1 Hsich RC. Fine BS, Lyons JS. Patterned dystrophies of the retinal pigment epithelium. Arch Ophthalmol 1977; 95: 429-35.

2 Marmor MF, Byers B. Pattern dystrophy of the pigment epithelium. Am J Ophthalmol 1977; 84: 32-44.

3 Sjögren H. Dystrophia reticularis laminae pigmentosae retinae. An earlier not described hereditary eye disease. Acta Ophthalmol (Kbh) 1950; 28: 279-95.

4 Deutman AF, Van Blommestein JDA, Henkes HE, Waardenburg PJ, Solleveld-Van Driest E. Butterfly-shaped pigment dystrophy of the fovea. Arch Ophthalmol 1970; 83: 558-69.

5 Mesker RP. Oosterhuis JA, Delleman JW. A retinal lesion resembling Sjögren's dystrophia reticularis laminae pigmentosac retinae. In: Winkelman JE, Crone RA, eds. Perspectives in ophthalmology. Amsterdam: Excerpta Medica, 1970; 2: 40-5.

6 Best F. Ueber eine hereditare Maculaaffektion: Beitrage zur Verebungslehre. Z Augenheilkd 1905; 13: 199-212.

7 Gutman I, Walsh JB, Henkind P. Vitelliform macular dystrophy and butterfly-shaped epithelial dystrophy: a continuum? $\mathrm{Br} J$ Ophthalmol 1982; 66: 170-3.

8 Lodato G, Giuffrè G. Associations inusuclles dans les dystrophics en réseau. J Fr Ophtalmol 1985; 8: 147-54.

9 Giuffrè G. Morning glory syndrome: clinical and electrofunctional study of three cases. BrJ Ophthalmol in press.

10 Weingeist TA, Kobrin JL, Watzke RC. Histopathology of Best's macular dystrophy. Arch Ophthalmol 1982; 100: 1108-14.

11 Frangich GT, Green WR. Fine SL. A histopathologic study of Best's macular dystrophy. Arch Ophthalmol 1982; 100: 1115-21.

12 Watzke RC, Folk JC, Lang RM. Pattern dystrophy of the retinal pigment epithelium. Ophthalmology (Rochester) 1982; 89: $1400-6$.

13 De Jong PTVM, Delleman JW. Pigment epithelial pattern dystrophy. Arch Ophthalmol 1982; 100: 1416-21.

14 Girard P, Setbon G, Forest A, Coscas G. Dystrophies en réseau de l'épithélium pigmentaire. J Fr Ophtalmol 1980); 3: 101-6.

15 Cardillo Piccolino F, Castellazzo R, Vittone P. Su un caso di distrofia pigmentaria maculare di particolare morfologia. Boll Oculist 1979; 58: 207-10.

16 Maucione V, Neushuler R, Zitelli G. Su di un caso di distrofia pigmentaria della macula di dubbia interpretazione. Ann Ottalmol Clin Oculist 1980; 106: 495-500. 
17 Amantia L. Distrofia epitelio-pigmentaria maculare familiare atipica. In: Proc 63 Congr Soc Oftalmol Ital. Bologna: Capclli, 1983: 569-80.

18 Dcutman AF. The hereditary dystrophies of the posterior pole of the eye. Assen: Thomas, 1971: 198-299.

19 Krill AE. Vitclliform macular dystrophy. In: Krill AE, ed. Hereditary retinal and choroidal disease. Hagerstown: Harper and Row, 1977: 2: 665-7()4.

20) Benson WE, Kolker AE, Enoch JM, Van Loo JA, Honda Y. Bcst's vitelliform macular dystrophy. Am J Ophthalmol 1975; 79: $59-66$.
21 Miller SA, Bresnick GH, Chandra SR. Choroidal neovascular membranc in Best's vitelliform macular dystrophy. A m J Ophthalmol 1976; 82: 252-5.

22 Fishman GA, Woolf MB, Goldberg MF, Busse B. Reticular tapeto-retinal dystrophy. As a possible late stage of Sjögren's reticular dystrophy. BrJ Ophthalmol 1976; 60: 35-40).

23 Prensky JG, Bresnick GH. Butterfly-shaped macular dystrophy in four generations. Arch Ophthalmol 1983: 101: $1198-203$

Accepted for publication 7 November 1985. 